www.jmscr.igmpublication.org

Index Copernicus Value: 79.54

ISSN (e)-2347-176x ISSN (p) 2455-0450

crossref DOI: https://dx.doi.org/10.18535/jmscr/v7i4.01

\title{
Association of Vitamin D deficiency and Hypothyroidism in a tertiary teaching hospital in Kerala
}

\author{
Authors \\ Suma Samuel ${ }^{1}$, Jacob K Jacob ${ }^{2}$,Jilse George ${ }^{3}$, Manjula V.D. ${ }^{4}$ \\ ${ }^{1}$ Asst Professor of Medicine, ${ }^{2}$ Professor of Medicine, \\ ${ }^{3}$ Professor and HOD Dept of Medicine, ${ }^{4}$ Professor and HOD Dept of Community Medicine, \\ Government Medical College, Ernakulam, Kerala, India
}

\begin{abstract}
Background: Vitamin D deficiency is a global health issue and is associated with myriad health disorders. Objective: To study the association of Vitamin D levels in hypothyroid patients to find out if low levels of Vitamin D is contributing to hypothyroid states.

Materials and Methods: A cross sectional case control observational study in a single center. The study was conducted in Government Medical College, Ernakulam in the medical department. Vitamin D levels in 60 hypothyroid patients which formed the case group and 60 matched control group was estimated using the Chemiluminescent immune assay during June2016 to December 2018, after obtaining approval of the Institutional Ethics Committee.

Results and Conclusions: This study has revealed that there was a significant number of patients with Vitamin D insufficiency in both groups with a statistically significant difference in females outnumbering males in vitamin D deficiency. However it was found that Vitamin D insufficiency was not present among hypothyroid patients significantly compared to euthyroid patients in the given study population.

Recommendations: The significant prevalence of low vitamin D levels in our population should be highlighted much more and should be a matter to bring in to more public awareness.
\end{abstract}

\section{Introduction}

The role of vitamin D has been evolving since it's discovery in the early $20^{\text {th }}$ century from being a simple vitamin to a steroid pro hormone. Vitamin $\mathrm{D}$ is known as the sunshine vitamin. It is obtained from the diet or synthesized in the human skin on exposure to ultraviolet irradiation. Vitamin D mediates it's effects through binding to vitamin D receptors (VDR) and activation of VDR responsive gene. ${ }^{1}$

Vitamin D receptors (VDR) are found in most tissues of the body. It has a main role in calcium and phosphorous homeostasis and bone strength. Both Vitamin D and thyroid hormone bind to similar receptors called steroid hormone receptors ${ }^{1}$. The discovery of VDR in other cells highlighted the potential involvement of vitamin $\mathrm{D}$ in autoimmune thyroid disorders. ${ }^{1} \mathrm{VDR}$ gene polymorphism was found to have an association with autoimmune thyroid disorders ${ }^{1}$.

Vitamin D levels have been noted to have non skeletal roles in autoimmune disorders like Hashimoto's thyroiditis, Grave's disease, Type 1Diabetes mellitus, Rheumatoid arthritis, SLE 
andatherosclerosis. ${ }^{2}$ Impaired vitamin D signaling has been reported to encourage thyroid disorders $3,4,5$

Previous studies have reported that Hashimoto's thyroid disorder had lower vitamin D levels. However Indian studies have shown a weak connection between low vitamin D levels and hypothyroidism. So far the research on its definitive role in thyroid disease is not conclusive. Hence, in the current scenario of low Vitamin D levels in a large section of the population and the same being the causative factor in numerous illnesses and with the high prevalence of hypothyroidism in the community without a definite etiology in all cases, this study was conducted to find out if any association between the two exists in the given population.

\section{Review of Literature}

This review is based on an internet search of literature published from 2009-2018 using the title of Vitamin D deficiency in thyroid disorders. The references of selected papers are included.

There is a higher prevalence of Vitamin D deficiency and hypothyroidism in the Indian population $^{3}$. Despite adequate sunshine in India, Vitamin D deficiency in India is prevalent around $50-90 \%{ }^{6,7}$

Association studies between low Vitamin D levels and hypothyroidism have given mixed results ${ }^{8}$. Several epidemiological studies have shown an association between low levels of vitamin D and autoimmune diseases like Type 1 DM, Rheumatoid arthritis, Multiple sclerosis, Inflammatory bowel disorder 8,9,10,11,12,2

A study done by Amal et al in Saudi Arabia showed a significant positive correlation with serum vitamin D and serum calcium level. ${ }^{13} \mathrm{~A}$ study done in Northern India by Goswami et al demonstrated only a weak association of vitamin $\mathrm{D}$ deficiency with autoimmune disease ${ }^{14}$. But a similar study done in Eastern India by Holder et al showed a significant low level of Vit D level in autoimmune thyroid disorders than in controls ${ }^{15}$.A study done in Trivandrum showed a significant association of Vitamin D deficiency with Hashimoto's thyroiditis ${ }^{16}$. The North Bengal study showed that hypothyroid patients were frequently associated with vitamin D deficiency ${ }^{17}$

Vitamin D deficiency has been noted to have seasonal variation with Vitamin D deficiency more during colder seasons. ${ }^{18,19}$ Nagmeh et al observed that a significant proportion of Vitamin D deficiency had reported symptoms of brain fog, low mood, poor sleep, weight gain or low energy $^{20}$

If there was conclusive evidence, Vitamin D supplements could offer a economical approach for autoimmune thyroid disorders and provide protection from developing thyroid disorders ${ }^{20}$. However there is a scarcity of clinical trials on effects of Vitamin D supplements on thyroid function. A 12 week study showed Vitamin D supplements in hypothyroid patients improved T3 and $\mathrm{T} 4 .^{21}$ Studies as mentioned above suggest a probable clinical effect ${ }^{20,21,22,23,24}$

We undertook a study to observe the association of vitamin D levels in hypothyroid patients who attended the Government Medical College, mainly medical outpatients.

\section{Materials and Methods}

Objective: To study the association of Vitamin D levels in hypothyroid patients to find out if low levels of Vitamin D is contributing to a lower thyroid status.

Study Design: The study was a cross sectional case control observational study in a single center. Vitamin D levels in 60 hypothyroid patients which forms the case group and 60 matched control group was estimated after obtaining approval of the Institutional Ethics Committee.

Study Setting: The study was conducted in Government Medical College, Ernakulam in the medical department. Sixty cases of hypothyroid patients who attended the medical OPD or were inpatients and sixty matched controls who had normal TSH values were taken. The case and control group were all adults aged 18 years and 
above of both gender. The participants all lived in and around Ernakulam district in Kerala.

Sample Size: 60 cases and 60 controls.

Study Period: June 2016 to December 2018

Study Method: The case group enrolled 60 consecutive patients who were diagnosed with hypothyroidism and was on treatment. Corresponding control group also had 60 participants who were euthyroid and their TSH values were normal. The case and control group was age, sex and occupation matched (indoor or outdoor work). The research protocol was explained and written informed consent was taken from both case and control group. Their demographics, clinical examination and laboratory investigations for TSH and vitamin D level were done and entered on a proforma. Vitamin D level was estimated by the Chemiluminescent macro particle immuno assay with $5 \mathrm{ml}$ of venous blood. Vitamin D deficiency was defined as levels less than 10ng/dl and values in between 10 and 30 $\mathrm{ng} / \mathrm{ml}$ was defined as insufficient levels. Vitamin D sufficient level was defined as level greater than $30 \mathrm{ng} / \mathrm{ml}$. The following information were gathered: age, gender, religion, occupation as indoor or outdoor, presence or absence of thyroid swelling, TSH value, vitamin D levels and dose of hormone replacement in hypothyroid patients

Inclusion criteria: Cases were hypothyroid patients and controls were euthyroid. Adults aged 18 and above both males and female
Exclusion criteria: Those who had Diabetes Mellitus, Chronic kidney disease, Connective tissue disorder, On Vitamin D supplements, Malignancy.

Statistical Analysis: Data was collected in the excel format and results were analysed by the SPSS software. Analysis was done using odd's ratio and chi square. $\mathrm{P}$ value $<0.05$ was taken as significant

\section{Results}

A total of 120 subjects were studied: Males 7 (5.8\%); Females 113 (94.2\%). Mean age of control group was 48.35 and case was 44.7. Patients with Vitamin D insufficiency were younger and predominantly female. Mean serum TSH was 8.004 in hypothyroid patients. Mean serum TSH was 2.29 in euthyroid patients. Mean serum vitamin D level in Case was 16.82. Mean serum vitamin D level in control 17.42. In cases, Vitamin D deficiency was 10(16.7\%), insufficiency $44(73.3 \%)$ and sufficient levels were noted in $6(10 \%)$ patients. In control group, Vitamin D deficiency was 7 (11.7\%), insufficiency $49(81.7 \%)$ and sufficient levels were seen in $4(6.6 \%)$. Those who were vitamin D insufficient and deficient were treated with vitamin D tablets with a dose 60,000 IU once weekly for 8 weeks. No relation between Vitamin $\mathrm{D}$ and seasonal variation was noted. No differences in vitamin D levels were noted when religions were compared.

Table 1 Age and sex Distribution of study population

\begin{tabular}{|l|c|c|c|}
\hline Age grp & Male & Female & Total \\
\hline$<30$ & $1(9.1 \%)$ & $10(90.9 \%)$ & $11(100 \%)$ \\
\hline $30-60$ & $4(4.3 \%)$ & $88(95.7 \%)$ & $92(100 \%)$ \\
\hline$>60$ & $2(11.8 \%)$ & $15(88.2 \%)$ & $17(100 \%)$ \\
\hline Total & $7(5.8 \%)$ & $113(94.2 \%)$ & $120(100 \%)$ \\
\hline
\end{tabular}

Table 2 Comparison of TSH and Vit D of cases and controls

\begin{tabular}{|l|c|c|c|c|}
\hline & Mean & SD & $95 \%$ Confidence level & P value \\
\hline TSH (Case) & 8.004 & 9.00 & $5.67-10.32$ & 0.001 \\
\cline { 1 - 4 } TSH(Control) & 2.29 & 1.04 & $2.02-2.55$ & \\
\cline { 1 - 4 } Vit D (case) & 16.82 & 7.52 & $14.88-18.77$ & \multirow{2}{*}{0.650} \\
\cline { 1 - 4 } Vit D (Control) & 17.42 & 6.76 & $15.67-19.16$ & \\
\hline
\end{tabular}




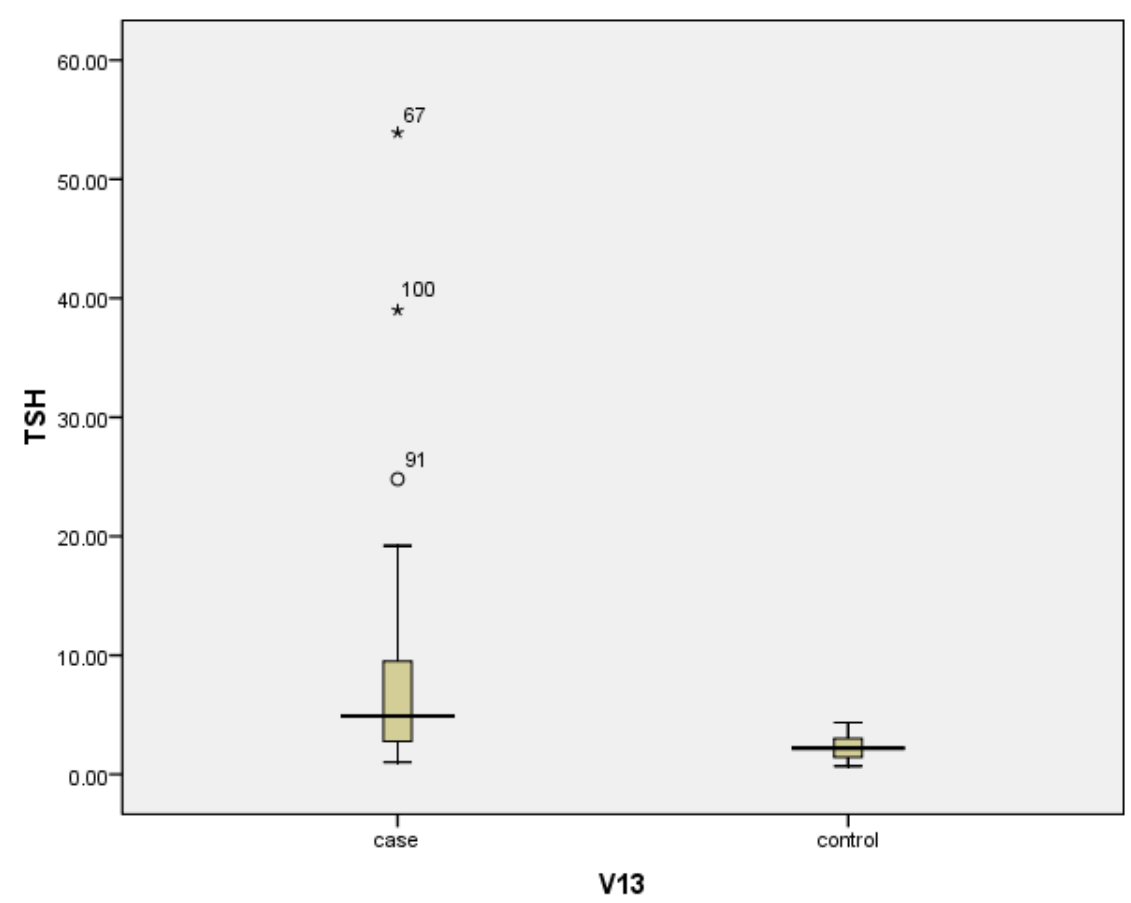

Fig 1 Box and whisker plot showing the descriptive of TSH in Case and control

Table 3 Correlation between TSH and Vit D among cases and controls

\begin{tabular}{|l|c|c|}
\hline & Correlation co-efficient & P Value \\
\hline Case & 0.224 & 0.08 \\
\hline Control & 0.253 & 0.05 \\
\hline
\end{tabular}

Table 4 Vit D Status among cases and controls

\begin{tabular}{|l|c|c|c|c|}
\hline & Insufficient & Deficient & Sufficient & Total \\
\hline Case & $44(73.3 \%)$ & $10(16.7 \%)$ & $6(10.0 \%)$ & $60(100 \%)$ \\
\hline Control & $49(81.7 \%)$ & $7(11.7 \%)$ & $4(6.6 \%)$ & $60(100 \%)$ \\
\hline Total & $93(77.5 \%)$ & $17(14.2 \%)$ & $10(8.3 \%)$ & $120(100 \%)$ \\
\hline
\end{tabular}

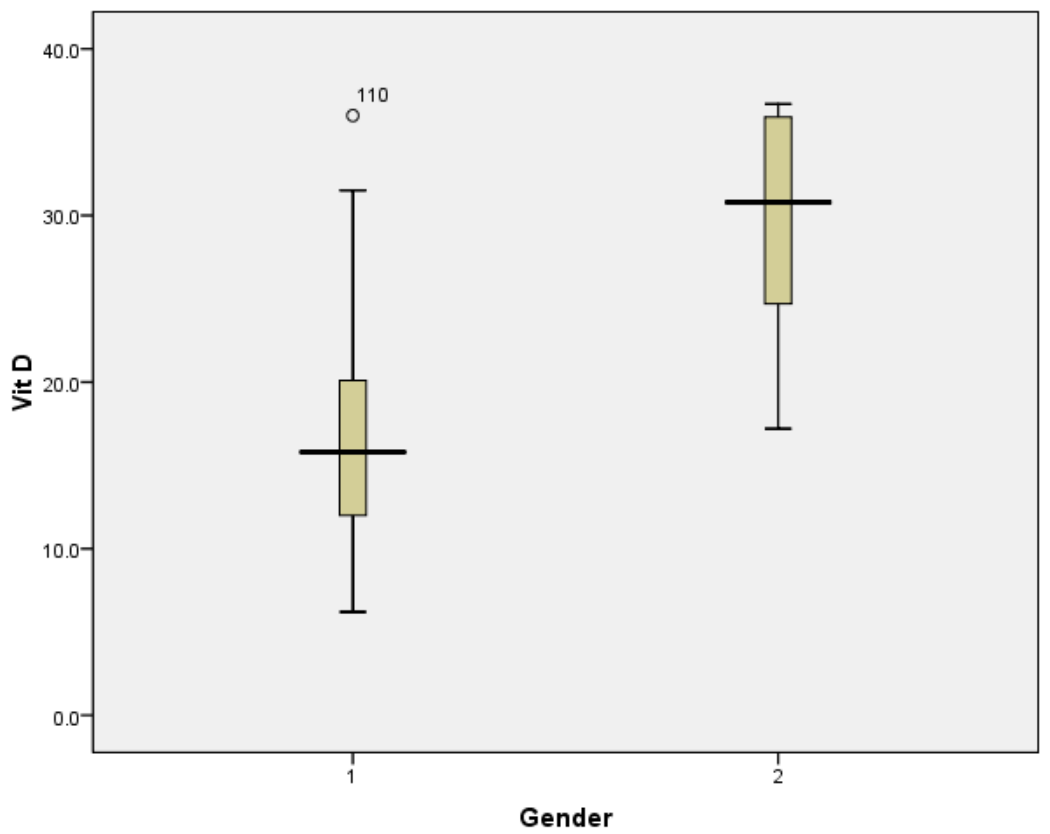

Fig 2 Box and whisker plot showing the descriptive of gender 1-Female, 2-Male 
Table 5 Comparison of vitamin D according to gender

\begin{tabular}{|l|c|c|c|c|c|}
\hline & Number & Mean & SD & $95 \%$ CI & P value \\
\hline & & & & & \multirow{2}{*}{0.005} \\
\cline { 1 - 5 } Male & 7 & 29.42 & 8.05 & $21.97-36.87$ & \\
\hline Female & 113 & 16.36 & 6.37 & $15.18-17.55$ & \\
\hline
\end{tabular}

Table 6 Distribution of Vitamin D status according to age group

\begin{tabular}{|l|c|c|c|c|}
\hline Age group & Insufficient & deficient & Sufficient & Total \\
\hline$<30$ & $8(72.7 \%)$ & $2(18.2 \%)$ & $1(9.1 \%)$ & 11 \\
\hline $30-60$ & $72(78.3 \%)$ & $15(16.3 \%)$ & $5(5.4 \%)$ & 92 \\
\hline$>60$ & $13(76.5 \%)$ & 0 & $4(23.5 \%)$ & 17 \\
\hline Total & $93(77.5 \%)$ & $17(14.2 \%)$ & $10(8.3 \%)$ & 120 \\
\hline & & & & $\mathrm{P} 0.07$ \\
\hline
\end{tabular}

\section{Discussion}

Our study showed a significant number of patients with insufficient vitamin D levels. A statistical significance of Vitamin D insufficiency was noted in females compared to males. Vitamin D deficiency was noted in both hypothyroid patients and euthyroid patients. Most vitamin D insufficiency and deficiency were noted in the middle age group

A study done by Rajeev et al concluded that most hypothyroids had serum vitamin $\mathrm{D}$ below $20 \mathrm{ng} / \mathrm{ml}^{25}$. Our study also showed a similar deficiency. Vitamin D deficiency could be due to dietary deficiency, reduced outdoor activity and sun exposure. The sunshine vitamin is deficient in the Indian population despite the abundance of sunlight $^{26}$

Significant decrease in females compared to males is widely prevalent in India. Our study also concurs with this observation. , $5,25,26,27$ which had a statistical significance.

\section{Conclusion:}

There was a significant number of patients with Vitamin D insufficiency in both groups. A statistically significant difference in females outnumbering males with vitamin D deficiency was noted. However it was found that Vitamin D insufficiency was not present among hypothyroid patients significantly compared to euthyroid patients in our study population.

\section{Recommendations}

The significant prevalence of low vitamin D levels in our population should be highlighted much more and should be a matter to bring in to more public awareness. Screening for Vitamin D deficiency among all age groups should be done due to its high prevalence. Further longitudinal long term study in a larger population in different ethnic and geographic populations is recommended to further confirm the association of low Vitamin D levels and hypothyroidism.

\section{Limitations of the study}

Small sample population.

\section{References}

1. Friedman Theodore C. Vitamin D deficiency and Thyroid disease www.goodhormonehealth.com/Vit D

2. Dohee Kim Int J Mol Sci 2017 Sep 18 (9):1949 published online2017 Sep12 The role of vitamin $\mathrm{D}$ in Thyroid diseasesPMC5618598

3. Unnikrishna AG, Kalra S, Sahay RK, Bantwal $G$ et al Prevalence of Hypothyroidism in adults. An epidemiological study in eight cities of India. Indian J Endocrinological Metabolism2013;17:647-52

4. Beloyartseva M, Mittal A, Kaur P, Kalra S et al Widespread Vitamin D deficiency among Indian health care professionals Arch Osteoporosis 2012,7: 187-92 
5. Marvaha RK, Tandon N, Garg MK, Kanwar $\mathrm{R}$ et al. Vitamin A status in healthy Indians aged 50 and above. J Assoc Phy India 2011,59:706-9

6. Harinarayanan CV and Joshi SR.2009 Vitamin D status in India-it's implications and remedial measures. J Assoc.Physicians India,57:40-48

7. Londhey, V 2011. Vitamin D Deficiency: Indian Scenario. Editorial J Assoc. Physicians. India,59:695-701

8. Idiculla J, Prabhu $\mathrm{P}$ Khadelkan $\mathrm{K}$ et al. Vitamin D and Primary hypothyroid. Is there an association? Thyroid Research Prac 2018; 15:34-7

9. Makariou S, LiberopoulosEN,Elisaf $\mathrm{M}$ et al 2011Novel roles of vitamin D in disease. What is knew in 2011? Eur J Intern Med22:355-362

10. Plum LA, De LucaHF, 2010 Vitamin D, disease and therapeutic opportunities. Nat Rev drug Discov 9: 941-955

11. Holick MF,2007 Vitamin D deficiency. N EnglJ Med357:266-281

12. Kivity S, Agmon-Levin,Zisappl $M$ et al 2011 Vitamin D and autoimmune thyroid diseases. Cell Mol Immunol8:243-247

13. Amal Muhammed Hussein, Budira et al. Vitamin D defi and it's association with thyroid disease. International journal of Health Science 2013 Nov: 7, (3) 267-275

14. Goswami R et al. Prevalence of vitamin D deficiency and it's relationship with thyroid autoimmunity in Asian Indians, a community based survey. British journalnutrition2009 Aug 102 (3) 382-6

15. Holder $T$, Bhattacharya S. Prevalence of Hypothyroidism and it's association with vitamin D deficiency in West Bengal, India. British journal of medicine, medical research (12) 7,1-10,2016

16. C Jayakumari, B Jayakumar, PK Jabbar et al 2017.Vitamin D deficiency-A risk factor for autoimmune thyroiditis. IJCIR,vol 3,issue 7:715-8
17. Arup Kumar Debsinha et al. Association of Vitamin D deficiency in hypothyroid population attending NBMC and Hospital.vol7,no 7 (2018). International journal of Scientific research.

18. Y wang, EJ Jacobs,M L Mc Cullough et al. Comparing methods methods for accounting for seasonal variability in a biomarker when only a single sample is available: insights from simulations based on serum 25 hydroxyvitamin D. Am J Epidemiol.170:88-94 2009

19. A Nauri,L H Foo,K Nakamura te al. Serum Vitamin D concentrations and season specific correrelates in Japanese adults. J Epidemiol 21:346-353 2011

20. NaghmehMirhosseini, Ludovic Brunei, Giovanna Muscogiuri et al. Endocrine 2017.Physiological serum 25hydroxyvitamin D concentrations are associated with thyroid functionobservations from a community based programme.58563-573

21. Al Saneh Talae, Fariba Ghorbani, Zhatollah Asemi-Effect of vitamin D supplement on thyroid function 2018/vol22/issue5:584-588

22. Chaudhary S, Dutta D, Kumar M, Saha S, Mondal SA, Kumar A, Mukhopadhyay S. Vitamin D supplementation reduces thyroid peroxidase antibody levels in patients with autoimmune thyroid disease: an open-labeled randomized controlled trial. Indian J. Endocrinol. Metab. 2016;20:391-398. doi: 10.4103/22308210.179997. [PMC free article] [PubMed] [CrossRef]

23. Mazokopakis EE, Papadomanolaki MG, Tsekouras KC, Evangelopoulos AD, Kotsiris DA, Tzortzinis AA. Is vitamin D related to pathogenesis and treatment of Hashimoto's thyroiditis? Hell J. Nucl. Med. 2015;18:222-227. [PubMed]

24. I.V. Pankiv, Impact of vitamin D supplementation on the level of thyroid 
peroxidase antibodies in patients with autoimmune hypothyroidism. Int. J. Endocrinol. (2016)

25. Rajeev Lohokare, Amita Gupta et al. A study of vitamin levels in hypothyroid patients ,a case contron study in a tertiary care hospital of central india. National journal of medical and dental research, January march 2016:volume4, issue 2 page89-92

26. GR Gupta A,VDD in India. Prevalence, casualties, interventions. Nutrientsb2014; $6729-75$

27. Harinarayan CV, Ramalakshmi T, Prasad UV et al Vitamin A status in Andhra Pradesh. A population based study. Indian J Med Res 2008;127:211-8. 